\title{
sciendo
}

\section{Impact of coronary artery tortuosity in ischemic and non-ischemic cardiovascular pathology}

\author{
DUMITRU EMILIAN MIHAI ${ }^{2,3}$, IOANA LUPASTEANU ${ }^{2}$, GHEORGHE ANDREI DAN $^{1,2,3}$ \\ ${ }^{1}$ Carol Davila University of Medicine and Pharmacy, Bucharest, Romania \\ ${ }^{2}$ Cardiology Department, Colentina Clinical Hospital, Bucharest, Romania \\ ${ }^{3}$ CDPC Cardiology Laboratory, Colentina Clinical Hospital, Bucharest, Romania
}

\begin{abstract}
The aim of this paper was to review based on the existing literature the impact of coronary artery tortuosity on coronary pathology. Primarily, an attempt was made to establish the implication of coronary tortuosity as a physio-pathological mechanism of inducing ischemia in patients with nonobstructive coronary artery disease (CAD). Because the prevalence of tortuosity is higher in severe hypertensive patients, a second purpose of this paper was to review this association by understanding the physio-pathological processes and fluid dynamics in hypertrophic heart. Particularly, the effect of coronary tortuosity on systolic function with reference to longitudinal function and ventricular relaxation was addressed. Finally, the technical difficulties imposed by coronary tortuosity to percutaneous coronary interventions were discussed.
\end{abstract}

Key words: coronary tortuosity, myocardial ischemia, arterial hypertension, systolic function, percutaneous coronary intervention.

\section{INTRODUCTION}

\section{Case report}

A 64-year-old male presented at the emergency room for chest pain associated with dyspnoea which started at rest two days before and lasted four hours. His clinical background reveal dyslipidaemia, type-2 diabetes and persistent atrial fibrillation. Physical examination showed no abnormalities with the exception of irregular pulse of $110 \mathrm{bpm}$. Laboratory findings show increased levels of high-sensitivity troponin $(1248 \mathrm{pg} / \mathrm{mL})$, NT-pro-BNP $(2649 \mathrm{pg} / \mathrm{mL})$ and LDL-cholesterol (108 mg/dL). The ECG showed atrial fibrillation, with a heart rate of $98 \mathrm{bpm}$, indeterminate QRS axis, pathologic Q wave in D II, D III, aVF with $1 \mathrm{~mm}$ ST-elevation in the same derivation and negative T wave in V4-V6 (Figure 1).

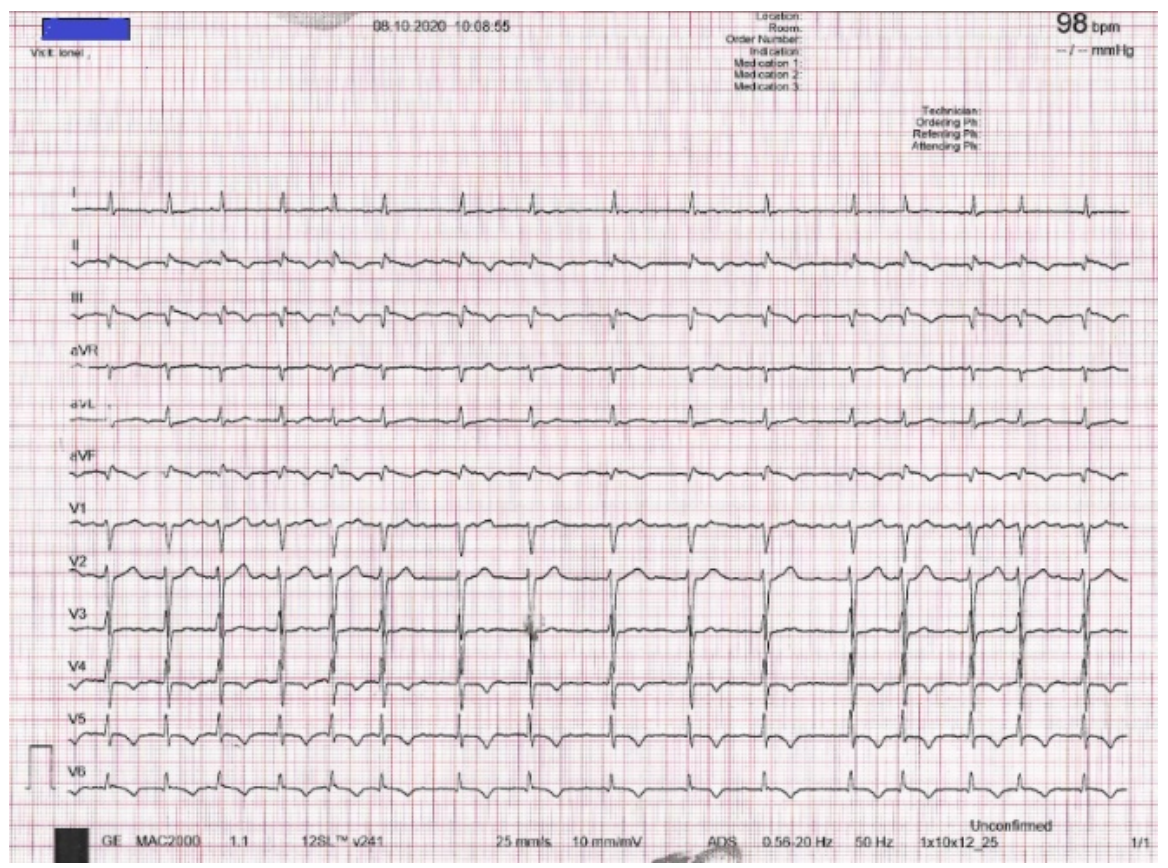

Figure 1. ECG at presentation. 
Echocardiography showed hypokinesia in the basal half of the inferior wall and moderate reduced ejection fraction.

We considered the diagnosis of late presentation inferior STEMI and proceed to coronarography. This investigation showed no visible atheromatous plaque, but with significant coronary tortuosity of the obtuse marginals (Figure 2).

The final diagnosis was MINOCA and the patient was treated with NOAC, beta-blocker, statin, IECA, thiazide-like diuretic and amiodarone after electrical conversion to sinus rhythm.

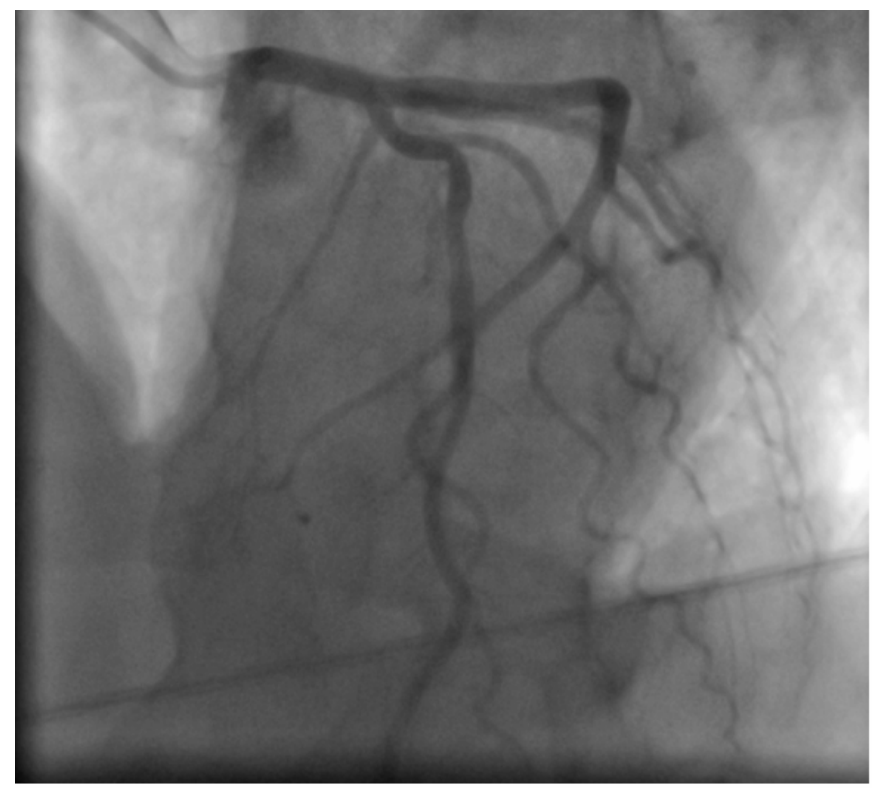

Figure 2. According to AHA/ACC Stenosis Morphology Classification in Percutaneous Interventions this patient has moderate coronary tortuosity.

\section{Coronary circulation}

The coronary circulation is unique because the heart is directly involved in generating its own perfusion pressure and, at the same time, the systole influences the coronary flow. Since myocardial contraction is closely related to the coronary flow, the equilibrium between coronary blood supply and demand is crucial to the normal functioning of the myocardium [1].

The heart is an unique organ in which blood is supplied in an outside-in fashion. The coronary vascular tree consists of epicardial (capacitance) and intramural (resistance) vessels [2]. Capacitance vessels are represented by the epicardial coronary arteries, which further ramify forming sharp angles; they have an important elastic lamina and imply minimal resistance to blood flow during diastole. Resistance vessels are represented by the perforating arteries, which emerge in right angles, penetrate into the myocardium and have a trajectory up to the subendocardium. These vessels are responsible for the regulation of flow under stress conditions, across a wide range of perfusion pressures [3]. Finally, the myocardial arterioles supply myocardial capillary beds and form a dense and extensive network (aprox.
3,000-4,000 capillaries $/ \mathrm{mm}^{2}$ ). At that level the distance between capillaries is less than $20 \mu$ [4]. The prevailing belief is that coronary flow is phasic in that compressive systolic forces compete with the driving forces for flow in the coronary circulation and consequently the majority of antegrade flow occurs during diastole. Secondary, the antegrade flow during systole fill the upstream coronary compliance, while the flow in the capillaries is quite steady. The systolic compressive forces are so powerful that the coronary circulation may undergo transient periods of retrograde flow during cardiac cycle [5].

\section{Coronary artery tortuosity: physio-pathological considerations}

Coronary artery tortuosity (CAT) is a curve modification of the coronary vascular tree frequently encountered during invasive and non-invasive imaging investigations. Its incidence varies between 12 and $40 \%$ in clinical trials that have addressed this topic $[6,7]$. CAT could be associated with age, arterial hypertension, atherosclerosis and genetic syndromes [8-11].

The mainly modulating factors for the geometry of the vascular system are hemodynamic forces, 
but particularly, for the coronary system, the cyclic flexion of the coronary artery may also be involved [12]. Research on animal models has demonstrated that arterial elongation, enlargement, and enhancement of tortuosity are adaptive responses to the exposure to high flow and high parietal stress. At tissular level, these may lead to smooth muscle cells and endothelial cells proliferation. Sho et al. found that in a rabbit arteriovenous fistula the arterial remodelling response after cycles of high flow and high wall stress is more uniform along the artery, despite exposure to the same initial flow conditions. Repeated closing and opening of the arteriovenous fistula conducted to sequential exposure of the artery wall to high flow and low shear stress. The common carotid artery elongated $37 \%$ after 4 weeks of high flow and it shortened $10 \%$ after 6 weeks of normal flow [13]. Since CAT is strongly associated with advanced age, another mechanism involved in its development is represented by the decrease in elastin in the arterial wall. Dobrin and Schwarcz performed experiments to appreciate longitudinal forces in pressurized arteries in vitro. In the dog vessels elastin was the only contributor to the longitudinal retractive forces during cyclic contractions, while in the human vessels both elastin and collagen exerts longitudinal retractive forces, with the elastin contributing the mostly [14].

\section{Coronary tortuosity: in search of a definition?}

A widely accepted clear definition of coronary tortuosity has not yet been established. The most frequently used definition is the one stated by AHA/ACC Stenosis Morphology Classification in Percutaneous Interventions in the late 1990s. This stratification includes three levels of severity. Mild tortuosity is defined by the existence of one curvature that changes the direction of a vessel $>2 \mathrm{~mm}$ in diameter at an angle $>45^{\circ}$, both in systole and diastole. Moderate tortuosity is defined by the presence of two consecutive curvatures and severe tortuosity by three consecutive curvatures (Figure 3) [15].

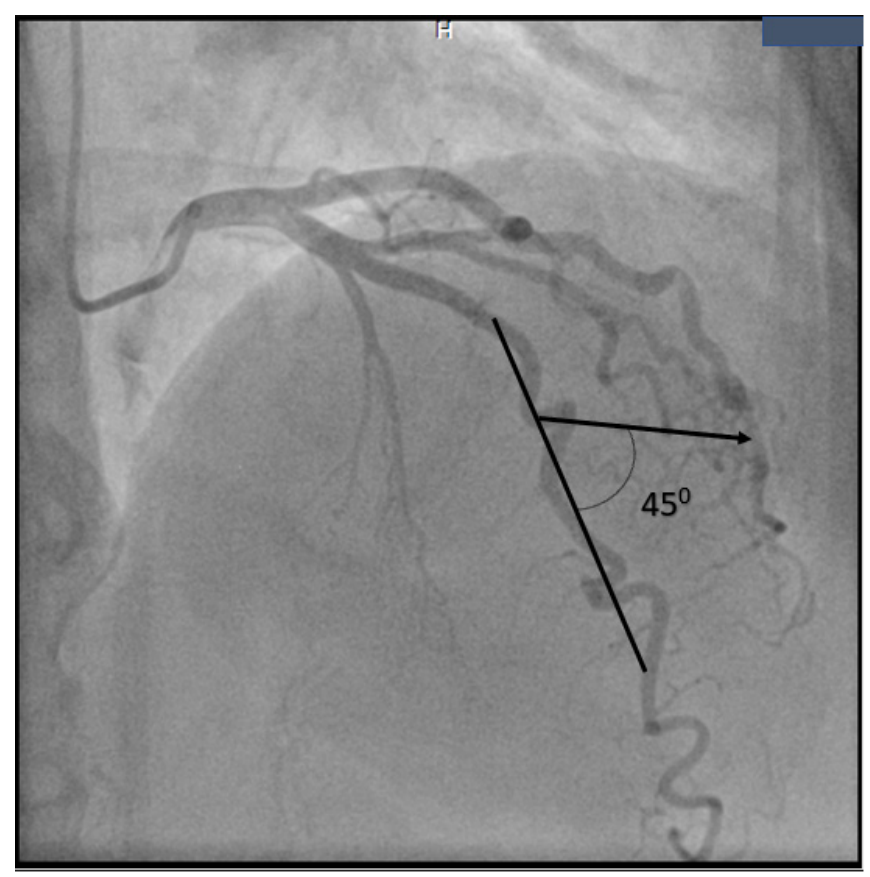

Figure 3. Definition of Coronary artery tortuosity stated by AHA/ACC Stenosis Morphology Classification in Percutaneous Interventions in the late 1990s.

In 2007, Zegers et al. defined coronary tortuosity as the succession of $\geq 3$ curvatures with $\geq 120^{\circ}$ deviation, during diastole [16]. In 2009, Groves et al. proposed an even more restrictive definition- the presence of $\geq 2$ consecutive curvatures with $>180^{\circ}$ deviation, in diastole [17]. In 2019, Jordy et al. published a study based on angio-CT and he obtained three-dimensional data regarding curvature, tortuosity and inflection points of epicardial coronary arteries, both in systole and diastole. Based on these data, the definition exceeds the classical concept represented by number and angle of curvatures and introduces an index of tortuosity as the ratio between the natural path length (L) and an imaginary straight line trajectory from the origin to a defined distal point (C) (Figure 4) [18]. 


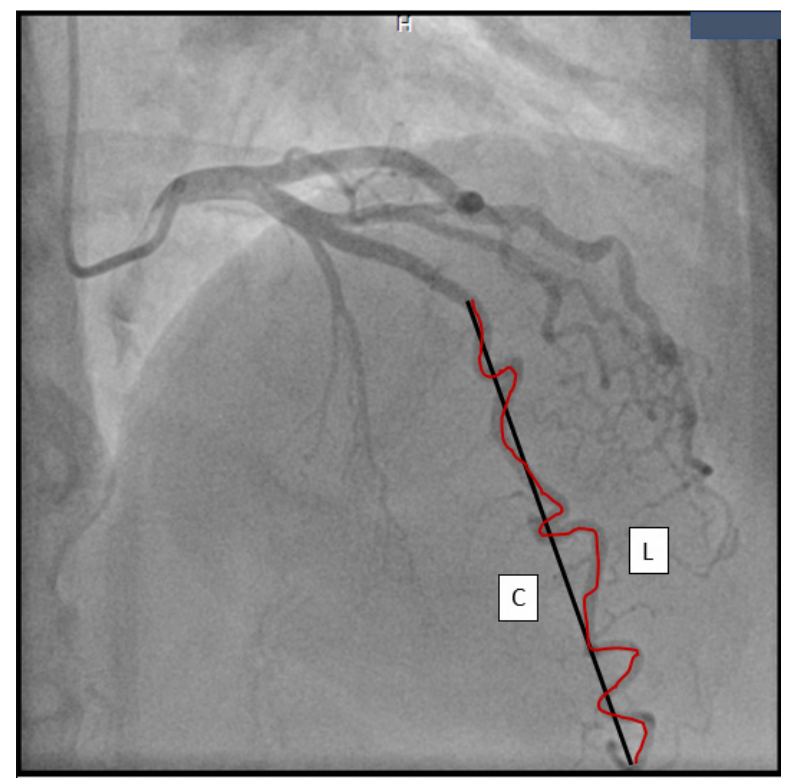

Figure 4. Definition of Coronary artery tortuosity proposed by Jordy et al. in 2019.

\section{Coronary tortuosity and myocardial ischemia}

Although overlooked in the past as a potential cause for myocardial ischemia, the contribution of CAT for myocardial ischaemia was reconsidered in the last decade [19]. In patients with significant atherosclerosis, several studies addressed the impact of coronary tortuosity on atherosclerotic proliferation, based on the principle that wall stress is the main causal factor for atherosclerotic plaques [20]. In patients with non-obstructive $\mathrm{CAD}$, flow alterations were emphasized, using myocardial perfusion imaging tests, both at rest and stress tests. Li and al. found that the incidence of myocardial perfusion defects was higher in the coronary tortuosity group compared to non-tortuosity coronary group. Multiple regression analysis showed that coronary tortuosity was significantly corelated to reversible myocardial defects [21]. Besides these physio-pathological considerations, the involvement of tortuosity in spontaneous dissections and aneurysms was also investigated as an ischemia generating mechanism [22].

There are relatively few studies that support the correlation between CAT and significant atherosclerosis. In these studies the hypothesis is based on the principle that parietal stress in the inner part of the curvature is low when the angle is $>120^{\circ}$, and therefore the curvature acts as the preferred location for coronary stenoses [24, 25]. In a study published in 1998, using IVUS, Iwami et al. determined that atherosclerotic plaques are distributed in the inner part of the curvature and that the lower the radius of the curvature, the more important the distribution of atherosclerosis at that level is [23]. Ayman et al. demonstrated a positive correlation between CAT severity index and significant coronary artery disease, but only in women. However, it is worth mentioning that a stenosis of $30 \%$ was considered significant in this study [24]. In 2016, analyzing the Coronary Calcium Score, El Tahlawi et al. established a significant association between $\mathrm{CAT}$ and a high $\mathrm{Ca}^{2+}$ score, regardless of the coronary stenosis grade [25]. In patients requiring $\mathrm{CABG}$, Levent and Zeynep proved in 2017 the statistically significant correlation between high SYNTAX score and CAT [26].

There are numerous studies that have established the connection between the presence of CAT and non-obstructive $\mathrm{CAD}$ in patients with typical angina. Gaibazzi et al. [27] observed that patients with typical angina, but with non-obstructive CAD and reversible myocardial perfusion defects on stress contrast echocardiography have a seven-fold increased prevalence of CAT and myocardial bridges. In the same study, half of the patients with "false positive" perfusion defects on stress contrast echocardiography had severe coronary tortuosity and myocardial bridging on coronary angiography. Among patients with angina and non-obstructive CAD, those with CAT and bridging: complained of recurrent angina on exertion, had ST depression on ECG effort test and reversible myocardial perfusion defects on stress echocardiography with contrast more frequently [27]. Another study published in 2012 by Li et al. noticed that CAT is associated with reversible perfusion defects in patients with stable angina and non-obstructive $\mathrm{CAD}$, the hypothesis being that tortuosity can lead to ischemia by lowering the 
pressure distally and therefore lowering the coronary flow reserve [21]. These two important studies demonstrate the association between CAT and reversible myocardial perfusion defects. However, the nature of the association is uncertain because it has not been proved whether CAT is the cause or just a marker of another mechanism.

\section{Coronary tortuosity in hypertensive patients}

In 1893, Thoma declared for the first time that "acceleration of flow leads to the vessel dilation and slowdown of flow leads to vessel narrowing" [28]. Since then, it has been widely recognized that arteries dilate in response to high blood flow and constrict in response to low blood flow. Kamya and Togawa demonstrated that the arteries rapidly change their diameter in order to maintain a relatively constant parietal stress, around 10-20 dynes $/ \mathrm{m}^{2}$. On long term, in response to a high wall stress, the arteries elongate, dilate and become tortuous [29]. The histopathological changes consist of proliferation of endothelial cells and smooth muscle cells and internal elastic lamina degeneration [30].

When flow passes through the arteries, perfusion pressure lowers due to a loss of energy. In tortuous arteries, there are supplementary losses of energy that can be explained by two mechanisms: friction due to parietal stress (friction is directly proportional to the vessel's length) and centrifugal forces [16].

The few clinical trials conducted in patients with arterial hypertension and coronary tortuosity demonstrated a strong association between them. In 1981 Torres (31) et al. divided 46 hypertensive patients into three groups: (1) patients with angina; (2) patients with left ventricular (LV) hypertrophy present on ECG; (3) patients without angina and LV hypertrophy on ECG. Patients in the first group had obstructive CAD (28\%) and CAT (95\%); patients in the second group had tortuosity $(75 \%)$; group 3 had tortuosity (70\%). Patients in groups 2 and 3 did not have significant coronary obstruction. One year later the same investigator Torres [31] selected a cohort of 70 patients who met ECG criteria of LV hypertrophy. These patients went through an ECG effort test, coronary angiography and left ventriculography. $84 \%$ of these patients had a "corkscrew" appearance of the coronary arteries on the angiography, without having significant atherosclerosis. At that time, it was presumed that subendocardial ischemia is related to the increase in LV mass and the decrease in coronary flow reserve [31]. Markus Jacob et al. [32] observed that, in hypertensive patients, the highest index of tortuosity was the end-diastolic one, while the endsystolic one was similar to the control group. The percentage by which the tortuosity index changed in systole versus diastole was the highest in hypertensive patients, but the lowest in those with chronic volume overload. This behaviour of the coronary arteries might be explained by the geometry of the heart, i.e. the larger the heart, the lesser tortuosity. Concentric hypertrophy is associated with high grade tortuosity, while the opposite is true in case of eccentric hypertrophy [32].

\section{Coronary tortuosity: LV systolic and diastolic function}

Evidence regarding the relation between CAT and LV systolic function is scarce at the moment. Oehler in 2017 [33], tried to determine if during systole, there is a correlation between coronary tortuosity and the grade of LV longitudinal shortening that deforms the longitudinally-distributed coronaries. His observations support the hypothesis that relative longitudinal shortening leads to sufficient deformation in the epicardial coronary arteries in order to produce shear stress-related coronary remodelling. The study was based on the concept that the "economy" of epicardial space during systole leads to coronary tortuosity. Epicardial surface suffer cyclic changes, decreasing during systole because of circumferential and longitudinal strain and increasing during diastole. This supposition is also supported by observations in female sex and increased LV mass who has small heart size and more frequently CAT. The implication is that the epicardial surface could be small relative to the ventricular mass. The results of the study challenge the assertion that LV hypertrophy and a higher flow demand alone, are sufficient to lead to CAT. Therefore, the authors concluded that, even though CAT increases parietal vascular stress over the curves, globally it could serve as a buffer for shear stress, distributing it evenly during exaggerated longitudinal shortening. Consequently, the fact that coronary artery disease is also a influenced by the flow heterogenicity, at least for this condition, this study results may further suggests that CAT may not be a maladaptive process, which could explain the lower incidence of coronary artery disease in those with CAT $[6,17]$.

The link between CAT and diastolic function has been investigated in a single study published by Turgut et al. [34] in 2007, the purpose of the study being to identify a causal relation between tortuosity 
and diastolic dysfunction, using echocardiographic data. Even there were no differences regarding systolic performance, for subjects with tortuosity, the E/A ratio was smaller compared with those without tortuosity. Patients with CAT had significantly longer deceleration time of $\mathrm{E}$ velocity and isovolumic relaxation time. Results revealed that patients with tortuous arteries have a higher incidence of diastolic dysfunction; to be noted that the total number of tortuous coronaries correlated with the echocardiographic parameters that reflect impaired LV relaxing.

\section{Coronary tortuosity and percutaneous coronary interventions: practical aspects}

CAT is always a challenge during percutaneous revascularization procedures, especially when associated with calcifications. It often leads to complications such as coronary dissection with or without complete vessel occlusion, partial or complete detachment of stents, multiple stenting with areas of stent overlapping and an increased difficulty in post-dilation [35]. The challenges associated with tortuosity increase the technical difficulty and decrease the success rate of PCI [36]. These techniques include intracoronary ultrasonography, optical coherence tomography, directional and rotational atherectomy, assessment of coronary pressure by fractional flow reserve and measurement of the index of microcirculatory resistance [37]. In addition, CAT is associated with lower rates of success in the recanalization of the obstruction in chronic coronary occlusions and in the reperfusion of acute coronary occlusions in case of ST-segment elevation myocardial infarctions. As the procedures require a longer duration, it leads to higher exposures to $\mathrm{X}$ radiations and contrast agent [37]. Furthermore, after the placement of guide wires, pseudo-lesions can be observed rather frequently. This phenomenon is known as the "Concertina effect" [37]; it occurs due to the vessel reconfiguration and can even lead

to transient vessel occlusion, the vessel visualization in distality being impossible. The inclusion of tortuosity in the SYNTAX score should be taken into account in the case of laborious procedures and redirect the patients towards cardiovascular surgery.

In order to surpass these inconveniences, several measures that can be implemented are: to obtain a good vessel preparation by multiple consecutive predilations, to over-intubate the guide wire for increasing the active support, to use extra-support guide wires, to use the Buddy wire technique by introducing an additional wire, to implant shorter thin-strut stents, to use side branch or distal anchoring techniques. Additional types of transit catheters are available, used in the "mother and child" system [38].

\section{CONCLUSIONS}

At this moment there is no unitary definition of coronary tortuosity, therefore, the implication for outcome is a subject of controversy.

Existing studies that address the connection between myocardial ischemia and coronary tortuosity induce the idea that we need to have a comprehensive approach regarding the global angiographic aspect of the coronary circulation. Although coronary tortuosity has a poor correlation with atherosclerotic lesions, it may induce ischemia by altering the distal coronary flow and oxygen supply as was recently proved. There is a strong association between CAT and hypertension, especially in female sex and advanced age. In hypertensive patient, high flow is decreased by supplementary energy loss in tortuous vessels through friction and centrifugal forces. Regarding the impact of systolic function on CAT, it has been acknowledged that coronary tortuosity is not a maladaptive response, but rather a coexistence in the need of space, especially in women with increased heart mass and normal left ventricle ejection fraction. The single study that investigated the relation between CAT and diastolic dysfunction determined an important association. As consequence of the many obstacles it poses, coronary tortuosity remains a technical challenge for the interventional cardiologist and implies frequent procedural complications and lower success rate of PCI.

Scopul acestei lucrări a fost să abordeze impactul tortuozităţii arterelor coronare asupra patologiei coronariene, pe baza cunoştinţelor existente. În primul rând, s-a incercat stabilirea rolului tortuozităţii coronariene ca mecanism fiziopatologic de inducere a ischemiei la pacienţii cu boală coronariană non-obstructivă. Deoarece prevalenţa tortuozităţii coronariene este mare la pacienţii mari hipertensivi, un al doilea scop al acestei lucrări a fost să reanalizeze această asociere prin inţ̧elegerea proceselor fiziopatologice şi a dinamicii fluidelor la nivelul cordului hipertrofic. 
În mod particular, a fost abordat efectul tortuozităţii coronariene asupra funcţiei sistolice cu referire la funcţia longitudinală şi asupra funcţiei diastolice. In finalul lucrării au fost discutate dificultăţile tehnice puse de tortuozitatea coronariană în cadrul procedurii de revascularizare coronariană percutană.

Correspondence to: Dumitru-Emilian Mihai, MD, Cardiology Department, Colentina Clinical Hospital, 19-21 Stefan cel Mare Street, Bucharest, Romania.

E-mail: mihaiemilian84@yahoo.com

Acknowledgements: The authors wish to thank Dr. Ioana Cristina Daha for offering the clinical case presented in this paper.

Conflict of interest disclosure: The authors declare no conflict of interest relevant for the publication of this paper.

\section{REFERENCES}

1. ARDEHALI A., PORTS TA. Myocardial oxygen supply and demand. Chest. 1990; 98(3):699-705.

2. ESTES EH., ENTMAN ML., DIXON HB., HACKEL DB. The vascular supply of the left ventricular wall. Anatomic observations, plus a hypothesis regarding acute events in coronary artery disease. Am Heart J. 1966; 71(1):58-67.

3. CHILIAN WM., EASTHAM CL, MARCUS ML. Microvascular distribution of coronary vascular resistance in beating left ventricle. Am J Physiol - Hear Circ Physiol. 1986; 251(4 (20/4)):779-88.

4. BASSINGTHWAIGHTE JB., YIPINTSOI T., Harvey RB. Microvasculature of the dog left ventricular myocardium. Microvasc Res. 1974; 7(2):229-49.

5. WIGGERS CJ. The physiology of the coronary circulation. In: Disease of the Coronary Arteries and Cardiac Pain, MacMilllan, New York, 1936:136-180.

6. LI Y., SHEN C., JI Y., FENG Y., MA G., LIU N. Clinical implication of coronary tortuosity in patients with coronary artery disease. PLoS One. 2011; 6(8):1-5.

7. ZHU H., DING Z., PIANA RN., GEHRIG TR., FRIEDMAN MH. Cataloguing the geometry of the human coronary arteries: A potential tool for predicting risk of coronary artery disease. Int J Cardiol [Internet]. 2009; 135(1):43-52.

8. PANCERA P., RIBUL M., PRESCIUTINNI B., LECHI A. Prevalence of carotid artery kinking in 590 consecutive subjects evaluated by Echocolordoppler. Is there a correlation with arterial hypertensio? 2000; J Intern Med. 2000; 248:7-12.

9. CORSO L D., MORUZZO D., AGELli M., ROMANELli AM. Tortuosity, Kinking, and Coiling of the Carotid Artery: Expression of Atherosclerosis or Aging? Angiology.1998; 49:361-371.

10. SMEDBY O., BERGSTRAND L. Tortuosity and Atherosclerosis in the Femoral Artery: What is Cause and What is Effect? Ann Biomed Eng. 1996; 24:474-480.

11. SATISH G., NAMPOOTHIRI S., KAPPANAYIL M. Images in Cardiovascular Medicine Arterial Tortuosity Syndrome Phenotypic Features and Cardiovascular Manifestations. Circulation. 2008; 117(23)477-478.

12. STEIN PD., HAMID MS., SHIVKUMAR K., DAVIS TP., KHAIA F., HENRY JW. Effects of cyclic flexion of coronary arteries on progression of atherosclerosis. Am J Cardiol. 1994; 73(7):431-7.

13. SHO E., NANJO H., SHO M., KOBAYASI M. Arterial enlargement, tortuosity, and intimal thickening in response to sequential exposure to high and low wall shear stress. J Vasc Surg. 2004; 39(3):601-12.

14. SCHWARCZ TH. Longitudinal Retractive Force in Pressurized Dog and Human Arteries. J Surg Res. 1990; 48 (2):116-20.

15. ZAACKS SM., ALLEN JE., CALVIN JE., SCHAER GL., PALVAS BW., PARILLO JE, et al. Value of The American College of Cardiology / American Heart Association Stenosis Morphology Classification for coronary interventions in the late 1990s. Am J Cardiol. 1998; 82(1):43-9.

16. ZEGERS ES., MEURSING BTJ., ZEGERS EB., OUDE OPHUIS AJM. Coronary tortuosity: A long and winding road. Netherlands Hear J. 2007; 15(5):191-5.

17. GROVES SS., JAIN AC., WARDEN BE., GHARIB W., BETO II RJ. Severe coronary tortuosity and the relationship to significant coronary artery disease. W V Med J. 2009; 105:14-17.

18. VAN ZANDWIJK JK., TUNCAY V., VLIEGENHART R., PELGRIM GJ., SLUMP CH., OUDKERK M, et al. Assessment of Dynamic Change of Coronary Artery Geometry and Its Relationship to Coronary Artery Disease, Based on Coronary CT Angiography. J Digit Imaging. 2020; 33(2):480-9.

19. ESTRADA APD., LOPES R de O., VILLACORTA JUNIOR H. Coronary tortuosity and its role in myocardial ischemia in patients with no coronary obstructions. Int J Cardiovasc Sci. 2017; 30(2):163-70.

20. WENTZEL JJ., CHATZIZISIS YS., GIJSEN FJH., GIANNOGLOU GD., FELDMAN CL., STONE PH. Endothelial shear stress in the evolution of coronary atherosclerotic plaque and vascular remodelling: current understanding and remaining questions. Cardiovasc Res. 2012; 96(2):234-43.

21. LI Y., LIU NF, GU Z Z., CHEN Y., LU J., FENG Y, et al. Coronary tortuosity is associated with reversible myocardial perfusion defects in patients without coronary artery disease. Chin Med J (Engl). 2012; 125(19):3581-3.

22. ELEID MF., GUDDETI RR., TWEET MS., LERMAN A., SINGH M., BEST PJ., et al. Coronary artery tortuosity in spontaneous coronary artery dissection angiographic characteristics and clinical implications. Circ Cardiovasc Interv. 2014; 7(5):656-62.

23. IWAMI T., FUJI T., MIURA., T, OTANI N., IIDA H., KAVAMURA A., et al. Importance of left anterior descending coronary artery curvature in determining cross-sectional plaque distribution assessed by intravascular ultrasound. Am J Cardiol. 1998; 82(3):381-4. 
24. HASSAN AKM., ABD-EL RAHMAN H., HASSAN SG., AHMED TAN., YOUSSEF AAA. Validity of tortuosity severity index in chest pain patients with abnormal exercise test and normal coronary angiography. Egypt Hear J. 2018; 70(4):381-7.

25. EL TAHLAWI M., SKRANA A., ELMURR A., GOUDA M., THARWAT M. The relation between coronary tortuosity and calcium score in patients with chronic stable angina and normal coronaries by CT angiography. Atherosclerosis. 2016; 246:334-7.

26. CERIT L., CERIT Z. Coronary Tortuosity; Component or Entire of SYNTAX Score Puzzle. Cardiovasc J Afr. 2017; 2(02):41-6.

27. GAIBAZZI N., RIGO F., REVERBERI C. Severe coronary tortuosity or myocardial bridging in patients with chest pain, normal coronary arteries, and reversible myocardial perfusion defects. Am J Cardiol. 2011; 108(7):973-8.

28. THOMA R. Untersuchungen über die Histogenese und Histomechanik des Gefäßsystems. Enke, Stuttgart; 1893.

29. KAMIYA A., TOGAWA T. Adaptive regulation of wall shear stress to flow change in the canine carotid artery. Am J PhysiolHear Circ Physiol. 1980; 8(1):14-21.

30. PEIFFER V., SHERWIN SJ., WEINBERG PD. Does low and oscillatory wall shear stress correlate spatially with early atherosclerosis? A systematic review. Cardiovasc Res. 2013; 99(2):242-50.

31. SÁNCHEZ TG., TREVETHAN CS., BIALOSTOZKY D., GUTIÉRREZ FE., OLVERA Cruz S. Clinical and coronary angiographic characteristics of hypertensive angina. Arch Inst Cardiol Mex. 1981; 51(6):541-7.

32. JAKOB M., SPASOJEVIC D., KROGMANN ON., WIHER H., HUG R., HESS OM. Tortuosity of coronary arteries in chronic pressure and volume overload. Cathet Cardiovasc Diagn. 1996; 38(1):25-31.

33. OEHLER AC., MINNIER J., LINDNER JR. Increased Coronary Tortuosity Is Associated with Increased Left Ventricular Longitudinal Myocardial Shortening. J Am Soc Echocardiogr. 2017; 30(10):1028-1034.

34. TURGUT O., YILMAZ A., YALTA K., YILMAZ BM., OZYOL A., KENDIRLIOGLU O. et al. Tortuosity of coronary arteries: An indicator for impaired left ventricular relaxation? Int J Cardiovasc Imaging. 2007; 23(6):671-7.

35. KARMPALIOTIS D., WYMAN MR., ALASWAD K., LOMBARDI W., RANGAN B V., LEMBO N, et al. Development and Validation of a Novel Scoring System for Predicting Technical Success of Chronic Total Occlusion Percutaneous Coronary Interventions. JACC Cardiovasc Interv. 2016; 9(1):1-9.

36. DISCIASCIO G., DELIGONUL U., TOPOL EJ. Coronary Morphologic and Clinical Determinants of Procedural Outcome With Angioplasty for Multivessel Coronary Disease Implications for Patient Selection. Circulation. 1990; 82(4):1193-202.

37. PAREKH P., AGRAWAL N., VASAVADA A., VINCHURKAR M. Extreme coronary artery tortuosity in association with tortuosity of the systemic arteries: A rare and challenging situation for the interventionist. BMJ Case Rep. 2014 (November).

38. SAEED B, BANERJEE S, BRILAKIS ES. Percutaneous Coronary Intervention in Tortuous Coronary Arteries: Associated Complications and Strategies to Improve Success. J Interv Cardiol. 2008; 21(6):504-11.

Received $19^{\text {th }}$ December 2020 